\title{
Pengetahuan tentang Menopause dengan Tingkat Kecemasan pada Wanita Premenopause di Rumah Sakit
}

\author{
Betti Sri Wahyuni, ${ }^{1}$ Ruswanti $^{2}$ \\ 1,2 Program Studi S1 Keperawatan \\ Sekolah Tinggi Ilmu Kesehatan Indonesia Maju \\ Jln.Harapan Nomor 50, Lenteng Agung -Jakarta Selatan 12610 \\ Telp: (021) 78894045 Email: hennijunitasimamora@gmail.com
}

\begin{abstract}
Abstrak
Perempuan akan mengalami perubahan fisiologis mulai dari masa reproduksi sampai masa klimakterium. Fase premenopause adalah fase yang dimulai usia 40 tahun dan dimulai masuk pada fase klimakterium yang ditandai dengan siklus haid yang tidak teratur, dengan perdarahan haid jarang dan jumlah darah haid yang banyak dan kadang diserta nyeri haid. Pada masa ini, wanita akan mengalami perubahan baik fisik maupun psikologis. Akibat perubahan ini, menimbulkan keluhan-keluhan yang dikenal dengan sindrom menopause. Pengetahuan perempuan tentang menopause akan sangat penting karena akan dapat menumbuhkan efek positif pada penataan kondisi psikologis diperlukan kesiapan mental dan pengetahuan yang cukup akan memudahkan seseorang dalam mengontrol depresi, kecemasan, serta gangguan emosional. Penelitian ini bertujuan untuk mengetahui hubungan antara pengetahuan tentang menopause dengan tingkat kecemasan pada wanita pramenopause di Rumah Sakit Harapan Bunda Jakarta Timur Tahun 2012. Desain penelitian yang digunakan adalah deskriptif korelasi dengan menggunakan pendekatan cross sectional. Teknik pengambilan sampel dengan metode purposive sampling yaitu sebanyak 67 orang klien di poliklinik kebidanan Rumah Sakit Harapan Bunda Jakarta Timur. Instrument pengumpulan data yaitu lembar kuesioner dan teknik analisa data dengan menggunakan chi-square. Hasil penelitian menunjukkan ada hubungan yang signifikan antara pengetahuan tentang menopause dengan tingkat kecemasan pada wanita premenopause dengan nilai $p$ value $0,041(<0,05)$. Berdasarkan hal tersebut diharapkan kepada klien agar lebih meningkatkan pengetahuannya sehingga tidak mengalami kecemasan yang berat menghadapi menopause.
\end{abstract}

Kata Kunci : Kecemasan, Pengetahuan, Menopause

\begin{abstract}
Women will experience physiological changes from the reproduction to the climacterium. The premenopausal phase is a phase that begins at 40 years and begins to enter in the climacteric phase characterized by irregular menstrual cycles, with rare menstrual bleeding and large amounts of menstrual blood and sometimes menstrual pain. At this time, women will experience both physical and psychological changes. As a result of these changes, there are complaints known as menopausal syndrome. Women's knowledge of menopause will be very important because it will be able to grow a positive effect on the arrangement of psychological conditions needed mental readiness and sufficient knowledge will allow a person in controlling depression, anxiety, and emotional disturbance. This study aims to determine the relationship between knowledge about menopause with anxiety levels in premenopausal women at Harapan Bunda Hospital Jakarta Timur 2012. The research design used is descriptive correlation by using cross sectional approach. Sampling technique with purposive sampling method that is as much as 67 clients in the obstetric policlinic Harapan Bunda Hospital East Jakarta. Instrument data collection is a questionnaire and data analysis techniques using chi-square. The results showed there was a significant relationship between knowledge about menopause with anxiety level in premenopausal women with $p$ value 0.041 ( <0.05). Based on it is expected to the client to further improve his knowledge so as not to experience severe anxiety facing menopause.
\end{abstract}

Keywords : Anxiety, Knowledge, Menopause 


\section{Pendahuluan}

Kemajuan dibidang kesehatan membuat tingkat angka harapan hidup menjadi meningkat, pada saat bersamaan populasi lansia juga meningkat.Berdasarkan sensus tahun 2000 jumlah perempuan usia diatas 50 tahun baru mencapai 15,5 juta orang atau 7,6\% dari total penduduk. Sementara itu, tahun 2020, jumlah diperkirakan meningkat menjadi 30 juta atau $11,5 \%$ dari total jumlah penduduk. Lebih lanjut, ditegaskan berdasarkan perhitungan statistik diperkirakan tahun 2020 jumlah penduduk Indonesia mencapai 262,6 jutajiwa dengan jumlah perempuan yang hidup dalam usia menopause yaitu antara 45-55 tahun adalah sekitar 30,3 juta jiwa. ${ }^{1}$

Manusia sepanjang hidupnya akan mengalami berbagai perubahan hingga pada masa penuaan, demikian pula halnya dengan perempuan. Fase terakhir dalam kehidupan perempuan atau setelah masa reproduksi berakhir dalam kehidupan perempuan atau setelah masa reproduksi berakhir yang disebut klimakterium, yaitu masa yang terjadi pada usia 45 sampai 50 tahun. Klimakterium adalah suatu masa peralihan yang dialami seorang wanita dari periode reproduktif ke periode non reproduktif.Tanda, gejala atau keluhan yang kemudian timbul sebagai akibat dari masa peralihan ini disebut sindrom premenopause. Periode ini berlangsung antara 5 sampai 10 tahun sekitar fase menopause ( 5 tahun sebelum dan 5 tahun sesudah menopause). ${ }^{2}$

Perempuan akan mengalami perubahan fisiologis mulai dari masa reproduksi sampai masa klimakterium. Fase premenopause adalah fase yang dimulai usia 40 tahun dan dimulai masuk pada fase klimakterium yang ditandai dengan siklus haid yang tidak teratur, dengan perdarahan haid jarang dan jumlah darah haid yang banyak dan kadang diserta nyeri haid. Sebagian faktor yang mempengaruhi gejala premenopause antara lain faktor psikologis dan fisik yang berhubungan dengan kadar estrogen. Gejala yang menonjol adalah berkurangnya tenaga dan gairah, mudah tersinggung, susah tidur dan ketakutan. Perubahan psikologis ini berbeda tergantung dari kemampuan perempuan untuk menyesuaikannya. ${ }^{3}$

Sindrom premenopause dirasakan hampir seluruh perempuan didunia yakni sekitar 70-80\% wanita Eropa, 60\% Amerika,
57\% Malaysia, 18\% Cina, 10\% Jepang dan di Indonesia $10 \%$. Berdasarkan beberapa data tahun 2005 tampak bahwa salah satu faktor dari perbedaan jumlah tersebut adalah pola makan wanita.Wanita Eropa dan Amerika mempunyai estrogen lebih banyak dari wanita Asia. Perempuan Eropa dan Amerika akanmengalami penurunan hormon yang drastis dibanding wanita Asia yang kadar estrogennya sedang, ketika menopause terjadi. ${ }^{4}$

Menopause akan dialami setiap wanita, namun keadaan ini tidak semua perempuan mengetahuinya dan dapat menerimanya. Umumnya, perempuan Indonesia mengalami menopause pada usia 45-55 tahun dengan berbagai faktor yang mempengaruhinya. ${ }^{5}$

Keluhan yang dirasakan pada sindrom menopause ini berupa keringat malam hari (night sweat), kekeringan pada vagina (drynessvaginal), insomnia, mudah lelah, sakit kepala, penurunan libido. Keluhan-keluhan yang dirasakan, secara psikologis menimbulkan emosi yang tidak stabil antara kecemasan yang terjadi dan terjadi perubahan-perubahan antara lain menurunnya daya ingat, cepat marah, sensitif, mudah tersinggung .

Wanita cemas bahwa apa yang dialaminya adalah suatu sakit yang menurutnya aneh dan tidak tahu sakit apa. Kecemasan adalah respon individu terhadap suatu keadaan yang tidak menyenangkan yang di alami oleh, semua makhluk hidup dalam kehidupan sehari-hari. ${ }^{7}$ Kecemasan timbul akibat reaksi psikologis individu terhadap ketidakmampuan mencapai orgasme dalam hubungan seksual. Energi seksual tidak terekspresikan akan mengakibatkan rasa cemas. ${ }^{8}$

Pengetahuan perempuan tentang menopause akan sangat penting karena akan dapat menumbuhkan efek positif pada penataan kondisi psikologis. Kesiapan mental dan pengetahuan yang cukup akan memudahkan seseorang dalam mengontrol depresi, kecemasan, serta gangguan emosional sangat mungkin menurunkan masalah tidur. $^{9}$

Berdasarkan studi pendahuluan yang dilakukan peneliti terhadap klien yang berobat di Rumah Sakit Harapan Bunda di ruang poliklinik kandungan, Jakarta Timur pada 
bulan April 2012 didapatkan 6 dari 10 klien (60\%) mengalami kecemasan. Mereka sering mengeluhkan keringat di malam hari dan adanya rasa panas di wajah. Hal ini menyebabkan kecemasan dan kekhawatiran mereka meningkat apalagi tidak jarang mereka merasakan dada berdebar-debar. Sementara 4 klien lain (40\%) mengetahui akan menopause dan gejala yang dapat terjadi. Klien ini mengatakan tidak merasakan kecemasan karena mereka menyadari akan masa umur yang akan tua dan pasti akan mengalami hal ini, mereka lebih pasrah menjalani hidup dan tidak mau melawan kodrat bahwa perempuan akan mengalami penuaan. Berdasarkan permasalah di atas, maka peneliti tertarik untuk mengambil judul hubungan pengetahuan tentang menopause dengan tingkat kecemasan pada wanita premenopause di Rumah Sakit Harapan Bunda Jakarta Timur Tahun 2012.

Tujuan umum mengidentifikasi pengetahuan perempuan tentang menopause di Rumah Sakit Harapan Bunda Jakarta Timur dan mengidentifikasi tingkat kecemasan perempuan pada masa premenopause di Rumah Sakit Harapan Bunda Jakarta Timur.

\section{Metode}

Penelitian ini dilakukan dengan menggunakan desain penelitiandeskriptif korelasi. Desain penelitian deskriptif korelasi bertujuan untukmengetahui hubungan antar variabel independen dengan variabel dependen yaitu hubungan pengetahuan tentang menopause dengan kecemasan pada wanita premenopause. ${ }^{10}$

Desain penelitian korelasi dalam penelititidak mencoba mencari hubungan sebab akibat, peneliti hanya menggambarkan hubungan antar satu variabel dengan variabel lainnya pada satu kelompok sampel.Penelitian ini dilakukan secara cross sectional yaitu pengumpulan data penelitian yang dilaksanakan sekaligus pada suatu saat. ${ }^{10}$

Populasi penelitian merupakan suatu objek yang diteliti. ${ }^{10}$ Populasi merupakan keseluruhan subjek penelitian. ${ }^{11}$ Populasi dalam penelitian iniadalah seluruh klien usia 45-55 tahun yang berobat di Rumah SakitHarapan Bunda Kecamatan Pasar Rebo Jakarta Timur berjumlah sekitar 200 orang.

Sampel adalah sebagian dari keseluruhan objek yang diteliti, yang dianggap mewakili seluruh populasi. ${ }^{10}$ Berdasarkan hasil perhitungan didapatkan bahwa sampel yang digunakan sebanyak 67 orang. Supaya tidak terjadinya drop out dari responden, sampel akan ditambahkan 3 dari jumlah sampel yang dibutuhkan, sehingga jumlah responden yang akan diberikan kuesioner adalah 70 responden. Kriteria inklusi yang ditentukan untuk subjek penelitian adalah sebagai berikut : Ibu yang berusia antara 45-55 tahun yang belum menopause. Bersedia menjadi responden dalam penelitian ini. Klien yang berobat di Rumah Sakit Harapan Bunda Kecamatan Pasar Rebo Jakarta Timur.

Teknik atau pengambilan sampel dalam penelitian ini dilakukansecara probality sampling yaitu teknik sampling yang memberikan peluang yang sama bagi setiap unsur (anggota) populasi untuk dipilih menjadi anggota sampel. Penelitian ini menggunakan tekhnik purposive sampling disebut juga judgement sampling adalah suatu teknik penetapan sampel dengan cara memilih sampel di antara populasi sesuai dengan yang dikehendaki peneliti (tujuan/masalah dalam penelitian), sehingga sampel tersebut dapat mewakili karakteristik populasi yang telah dikenal sebelumnya. ${ }^{12}$

Analisis univariat digunakan untuk menjelaskan dan mendeskripsikan karakteristik masing-masing variabel yang diteliti, baik variabel bebas (independen) maupun variabel terkait (dependen).

Nalisa univariat mendapatkan gambaran distribusi frekuensi atau besarnya proporsi menurut berbagai karakteristik variabel yang diteliti. Analisis univariat dalam penelitian ini adalah untuk menganalisis variabel pengetahuan dan gambaran variabel tingkat kecemasan. Analisis bivariat yang digunakan untuk melihat hubungan duavariabel yaitu variabel dependen dan variabel independen. Untukmembuktikan adanya hubungan antara dua variable tersebut dilakukan uji statistik Chi-Square.

Analisis ini bertujuan untuk melihat hubungan antara dua variabel yaitu variabel independen dan variabel dependen yaitu hubungan pengetahuan tentang menopause dengan tingkat kecemasan pada wanita premonopause. Agar dapat mengetahui hubungan antara dua variabel yaitu variabel 
bebas dan variabel terikat, ada uji yang di pakai yaitu uji Chi-Square. ${ }^{16}$

\section{Hasil}

\section{Analisis Univariat}

Tabel 1. Distribusi Frekuensi Responden Menurut Usia, Pendidikan, Status, Pekerjaan, Agama, Suku Bangsa, Jumlah Anak, Pengetahuan Klien dan Kecemasan Klien di Rumah Sakit Harapan Bunda Jakarta Timur Tahun 2012

\begin{tabular}{|c|c|c|}
\hline Variabel & (n) & (f) \\
\hline \multicolumn{3}{|l|}{ Usia } \\
\hline $40-48$ & 43 & 64,2 \\
\hline $49-55$ & 24 & 35,8 \\
\hline \multicolumn{3}{|l|}{ Pendidikan } \\
\hline TS & 13 & 19,4 \\
\hline SD & 13 & 17,9 \\
\hline SMP & 12 & 6 \\
\hline SMU & 25 & 37,3 \\
\hline SI & 8 & 1,9 \\
\hline \multicolumn{3}{|l|}{ Status } \\
\hline Menikah & 15 & 22,4 \\
\hline Janda & 21 & 31,3 \\
\hline Tidak menikah & 31 & 46,3 \\
\hline \multicolumn{3}{|l|}{ Pekerjaan } \\
\hline Buruh & 7 & 10,4 \\
\hline IRT & 11 & 16,4 \\
\hline PNS & 20 & 29,9 \\
\hline Swasta & 62 & 43,3 \\
\hline \multicolumn{3}{|l|}{ Agama } \\
\hline Islam & 25 & 37,3 \\
\hline Protestan & 14 & 20,9 \\
\hline Katolik & 13 & 19,4 \\
\hline Budha & 10 & 10,9 \\
\hline Hindu & 5 & 7,5 \\
\hline \multicolumn{3}{|l|}{ Suku Bangsa } \\
\hline Sunda & 14 & 20,9 \\
\hline Jawa & 37 & 55,1 \\
\hline betawi & 16 & 23,9 \\
\hline \multicolumn{3}{|l|}{ Jumlah Anak } \\
\hline Tidak punya & 1 & 1,5 \\
\hline $1-3$ anak & 54 & 80,6 \\
\hline$>3$ & 12 & 14,9 \\
\hline \multicolumn{3}{|c|}{ Pengetahuan Klien } \\
\hline Baik & 35 & 52,2 \\
\hline Buruk & 32 & 47,8 \\
\hline \multicolumn{3}{|l|}{ Kecemasan Klien } \\
\hline Ringan & 28 & 41,8 \\
\hline Berat & 39 & 58,2 \\
\hline
\end{tabular}

Sumber : Sistem Komputerisasi 2017

Data diatas menunjukkan distribusi frekuensi usia klien di Rumah Sakit Harapan Bunda Jakarta Timur Tahun 2012 dengan frekuensi terbanyak yaitu klien berusia 40-48 tahun sebanyak $43(64,2 \%)$ dari 67 responden sementara klien berusia 49-55 tahun ada 24
$(35,8 \%)$ dari 67 respondenn.Berdasarkan data tersebut dapat disimpulkan bahwa klien di Rumah Sakit Harapan Bunda Jakarta Timur Tahun 2012 sebagian besar berusia antara 4048 tahun. $\mathrm{Di}$ atas dapat dilihat bahwa pendidikan klien di Rumah Sakit Harapan Bunda Jakarta Timur Tahun 2012 terbanyak yaitu klien berpendidikan SMU 25 (37,3\%) dari 67 responden. Berdasarkan data tersebut maka dapat disimpulkan bahwa klien di Rumah Sakit Harapan Bunda Jakarta Timur Tahun 2012 sebagian besar berpendidikan SMU. Data diatas menunjukkan distribusi frekuensi status klien di Rumah Sakit Harapan Bunda Jakarta Timur Tahun 2012 dengan status terbanyak yaitu menikah sebanyak 31 $(46,3 \%)$ dari 67 responden. Berdasarkan data tersebut, maka dapat disimpulkan bahwa klien di Rumah Sakit Harapan Bunda Jakarta Timur Tahun 2012 sebagian besar berstatus menikah.

Data diatas menunjukkan distribusi frekuensi pekerjaan klien di Rumah Sakit Harapan Bunda Jakarta Timur Tahun 2012 dengan frekuensi terbanyak yaitu klien dengan pekerjaan pegawai swasta ebanyak $62(43,3 \%)$ dari 67 responden. Berdasarkan data tersebut, maka dapat disimpulkan bahwa pekerjaan klien di Rumah Sakit Harapan Bunda Jakarta Timur Tahun 2012 sebagian besar sebagai pegawai swasta. Data diatas menunjukkan distribusi frekuensi usia klien di Rumah Sakit Harapan Bunda Jakarta Timur Tahun 2012 dengan frekuensi terbanyak yaitu agama Islam sebanyak $25(37,3 \%)$ dari 67 responden. Berdasarkan data tersebut, maka dapat disimpulkan bahwa agama klien di Rumah Sakit Harapan Bunda Jakarta Timur Tahun 2012 sebagian besar beragama islam. Data diatas menunjukkan distribusi frekuensi suku bangsa klien di Rumah Sakit Harapan Bunda Jakarta Timur Tahun 2012 dengan frekuensi terbanyak yaitu klien bersuku bangsa Jawa sebanyak $37(55,1 \%)$ dari 67 responden. Berdasarkan data tersebut, maka dapat disimpulkan bahwa suku bangsa klien di Rumah Sakit Harapan Bunda Jakarta Timur Tahun 2012 sebagian besar bersuku Jawa. Data diatas menunjukkan distribusi frekuensi usia klien di Rumah Sakit Harapan Bunda Jakarta Timur Tahun 2012 dengan frekuensi terbanyak yaitu klien dengan jumlah anak 1-3 anak sebanyak $54(80,6 \%)$ dari 67 responden. Berdasarkan data tersebut, maka dapat disimpulkan bahwa jumlah anak klien di 
Rumah Sakit Harapan Bunda Jakarta Timur Tahun 2012 sebagian besar memiliki anak 1-3 anak.
Data diatas menunjukkan distribusi frekuensi usia klien di Rumah Sakit Harapan Bunda Jakarta Timur Tahun 2012 dengan frekuensi terbanyak yaitu klien dengan

\section{Analisis Bivariat}

Tabel 2. Hubungan Pengetahuan Tentang Menopause Dengan Tingkat Kecemasan Pada Wanita Premenopause di Rumah Sakit Harapan Bunda Jakarta Timur Tahun 2017

\begin{tabular}{|c|c|c|c|c|c|c|c|c|c|}
\hline \multirow{3}{*}{ Pengetahuan Klien } & \multicolumn{4}{|c|}{ Tingkat Kecemasan } & \multirow{2}{*}{\multicolumn{2}{|c|}{ Total }} & \multirow{3}{*}{ OR } & \multirow{3}{*}{$95 \% \mathrm{CI}$} & \multirow{3}{*}{$\mathbf{P}_{\text {value }}$} \\
\hline & \multicolumn{2}{|c|}{ Berat } & \multicolumn{2}{|c|}{ Ringan } & & & & & \\
\hline & $\mathbf{N}$ & $\%$ & $\mathbf{N}$ & $\%$ & $\mathbf{N}$ & $\%$ & & & \\
\hline Buruk & 18 & 56,3 & 14 & 43,8 & 32 & 100 & 3,214 & $(1,168-8,849)$ & 0,027 \\
\hline Baik & 10 & 28,6 & 25 & 71,4 & 35 & 100 & & & \\
\hline
\end{tabular}

Sumber : Data Primer 2017

pengetahuan baik $35(52,2 \%)$ dari 67 responden. Berdasarkan data tersebut, maka dapat disimpulkan bahwa pengetahuan klien di Rumah Sakit Harapan Bunda Jakarta Timur Tahun 2012 sebagian besar memiliki pengetahuan baik. Data diatas menunjukkan distribusi frekuensi usia klien di Rumah Sakit Harapan Bunda Jakarta Timur Tahun 2012 dengan frekuensi terbanyak yaitu klien yang memiliki kecemasan ringan sebanyak $39(58,2 \%)$. Berdasarkan data tersebut, maka dapat disimpulkan bahwa tingakat kecemasan klien di Rumah Sakit Harapan Bunda Jakarta Timur Tahun 2012 sebagian besar memiliki tingkat kecemasan ringan.Tabel diatas menunjukkan pengetahuan klien di Rumah Sakit Harapan Bunda Jakarta Timur Tahun 2012. Pada table tersebut dapat kita lihat bahwa pengetahuan klien yang buruk ada sebanyak 32 dari 67 respon, pengetahuan klien yang baik ada sebanyak 35 sementara tingkat kecemasan klien yang berat ada sebanyak 28 dan tingkat kecemasan yang ringan ada 39 dari 67 responden. Berdasarkan data tersebut maka dapat disimpulkan bahwa semakin baik pengetahuan klien semakin ringan kecemasan klien pada masa premenopause.

Hasil analisa bivariat menunjukkan pengetahuan klien yang baik sebanyak 35 orang dengan tingkat kecemasan ringan sebanyak 25 orang $(71,4 \%)$ dan 10 orang $(28,6 \%)$ yang memiliki tingkat kecemasan berat sementara pengetahuan klien yang buruk sebanyak 32 dengan tingkat kecemasan berat $18(56,3 \%)$ dan $14(43,8 \%)$ klien yang memiliki tingkat kecemasan ringan. Berdasarkan hasil penelitian tersebut maka dapat disimpulkan bahwa pengetahuan klien sangat berpengaruh terhadap tingkat kecemasan klien.Hal ini dapat dilihat dari hasil analisis bivariat yang menunjukkan nilai $\mathrm{p}$ value 0,027 yang artinya ada hbungan antara pengetahuan klien dengan tingkat kecemasan klien menopause.

Berdasarkan nilai $p$ value yang ada sebesar 0,027 kurang dari 0,05 yang artinya $\mathrm{H} 0$ ditolak maka dapat disimpulkan bahwa ada hubungan yang signifikan antara pengetahuan tentang menopause dengan tingkat kecemasan pada wanita premenopause di Rumah Sakit Harapan Bunda Jakarta Timur. Berdasarkan hasil analisis diperoleh nilai OR 3,214 hal ini menunjukkan bahwa pengetahuan yang baik mempunyai peluang untuk membuat tingkat kecemasan wanita ringan sebesar 3 kali dibanding dengan pengetahuan yang buruk.

\section{Pembahasan}

\section{Pengetahuan Kecemasan Klien Tentang Menopause}

Hasil penelitian menunjukkan bahwa responden yang memiliki pengetahuan buruk sebanyak 32 dari 67orang $(47,8 \%)$ di banding dengan responden yang memiliki pengetahuan baik yaitu sebanyak 35 dari 67 orang $(52,2 \%)$.

Pengetahuan merupakan hasil tahu dan ini terjadi setelah oran melakukan penginderaan terhadah objek tertentu. Penginderaan terjadi melalui panca indera manusia yaitu : indera penglihatan, penciuman, pendengaran, raba dan rasa. Sebagian besar pengetahuan manusia diperoleh 'melalui pendengaran dan penglihatan. Pengetahuan merupakan dasar untuk terbentuknya tindakan seseorang. ${ }^{17}$

Pengetahuan yang diperoleh seseorang sangatdipengaruhioleh berbagai sumber informasi yang didapatkan baik internet, surat kabar, tabloid atau majalah, radio, TV, pendidikan kesehatan, bahkan dari orang lain. ${ }^{3}$ Media informasi seperti digunakan sebagai sarana membantu seseorang dalam rangka upaya meningkatkan kesadaran dan kemauan untuk 
mengurangi kecemasannya.Wanita yang sering membaca jurnal-jurnal kesehatan akan memiliki pengetahuan yang cukup dan akan membantu wanita memahami serta mempersiapkan dirinya menjalani menopause dengan lebih baik. ${ }^{2} \mathrm{Hal}$ ini sejalan dengan penelitian yang dilakukan Sumini dengan judul Faktor-faktor yang Mempengaruhi Tingkat Kecemasan Menghadapi Menopause di Desa Karang Rejo Kecamatan Juana Kabupaten Pati. Hasil penelitian menunjukkan faktor informasi mempengaruhi tingkat kecemasan dalam menghadapi menopause, dan disarankan bagi wanita yang menghadapi menopause perlu memperdalam informasi tentang tanda dan gejala menopause yang dapat dipertanggungjawabkan kebenarannya agar dapat mengahdapi masa menopause dengan baik tidak penuh kecemasan. $^{18}$

\section{Kecemasan Klien Tentang Menopause}

Hasil penelitian menunjukan bahwa responden yang memiliki kecemasan berat sebanyak 28 orang dari 67 orang $(41,8 \%)$ di banding responden yang memiliki kecemasan ringan sebanyak 39 orang dari 67 orang $(58,2$ $\%)$.

Kecemasan sebagai gangguan alam perasaan yang ditandai dengan perasaan ketakutan atau kekhawatiran yang mendalam dan berkelanjutan, tidak mengalami gangguan dalam menilai realitas, kepribadian masih utuh perilaku dapat terganggu tetap masih dalam batas normal. ${ }^{19}$

Kecemasan adalah respon individu terhadap suatu keadaan yang tidak menyenangkan yang dialami oleh semua makhluk hidup dalam kehidupan sehari-hari. Faktor yang mempengaruhi kecemasan salah satunya adalah usia. Usia responden terbanyak dalam penelitian ini adalah 40-48 tahun. Sebagian besar wanita usia diatas 40 tahun tidak mengetahui gejala-gejala menopause dan tidak tahu kapan datangnya menopause, cemas dan takut dengan datangnya masa menopause, merasa tidak berguna lagi sebagai seorang wanita. ${ }^{20} \mathrm{Hal}$ ini sejalan dengan penelitian yang dilakukan oleh Nur Isyana Aprilia dengan judul "Faktor-faktor yang mempengaruhi tingkat kecemasan pada wanita premenopause di Kelurahan Darmo Kecamatan Wonokromo Surabaya Tahun 2007”, didapatkan hasil faktor usia mempengaruhi tingkat kecemasan wanita premenopause sebesar $65 \%$ responden dengan kelompok usia 45-49 tahun memiliki tingkat kecemasan berat. ${ }^{21}$

\section{Hubungan antara pengetahuan dan kecemasan pada klien premenopause}

Hasil analisis menunjukan bahwa klien premenopause didapatkan sebanyak $32(48,7$ $\%$ ) responden dengan pengetahuan klien buruk dan $35 \quad(52,2 \%)$ klien yang memiliki pengetahuan baik. Sedangkan kecemasan klien yang berat sebanyak $28(41,8 \%)$ responden dengan kecemasan ringan $39 \quad(58,2 \%)$ responden. Hasil uji chi-square diperoleh nilai $p$ value sebesar 0,041 <0,05 sehingga $\mathrm{H} 0$ ditolak. Berdasarkan hasi tersebut maka dapat disimpulkan bahwa ada hubungan yang signifikan antara pengetahuan tentang menopause dengan tingkat kecemasan pada wanita premenopause di Rumah Sakit Harapan Bunda Tahun 2012.

Kecemasan adalah respon individu terhadap suatu keadaan yang tidak menyenangkan yang dialami oleh semua makhluk hidup dalam kehidupan sehari-hari. ${ }^{7}$ Responden yang dikategorikan yang memiliki pengetahuan baik maka akan lebih mampu mengatasi kecemasan yang dialaminya. Sedangkan responden yang dikategorikan memiliki pengetahuan kurang cenderung mengalami kecemasan berat. Kecemasan bukan hanya sakit secara emosional tapi karena ada kesalahan dalam pengetahuan, semakin banyak pengetahuan yang diketahuinya maka kecemasan akan lebih mudah untuk diatasi. Setiap wanita yang akan memasuki masa menopause harus memiliki pengetahuan yang memadai tentang menopause agar dapat menjalani masa tersebut dengan tenang sehingga wanita tersebut tidak mengalami kecemasan. ${ }^{2}$

Hasil penelitian dilapangan menunjukkan bahwa pengetahuan wanita di Rumah Sakit Harapan Bunda sebagian baik sehingga tingkat kecemasan yang dialami oleh wanita tersebut sebagian besar ringan. Menurut Kasdu, setiap wanita yang akan memasuki masa menopause harus memiliki pengetahuan yang memadai tentang menopause agar dapat menjalani masa tersebut dengan tenang sehingga wanita tersebut tidak mengalami kecemasan. ${ }^{2}$ Hasil ini sejalan dengan penelitian yang dilakukan oleh Kholisah dengan judul Hubungan Antara Tingkat Pengetahuan dengan Persepsi Wanita Tentang 
Masa Menopause di RT.51 RW.10 Desa Sidoarjo Kecamatan Krian Kabupaten Sidoarjo, didapatkan hasil 32 dari 40 orang $(85 \%)$ responden memiliki pengetahuan kurang dan sebagian besar mempunyai persepsi negatif. ${ }^{22}$

\section{Kesimpulan}

Sesuai dengan tujuan peneliti berdasarkan pada analisis dan pembahasan pada bab sebelumnya, hasil penelitian yang dilakukan terhadap 67 wanita premenopause di Rumah Sakit Harapan Bunda di bagian poliklinik Kecamatan Pasar Rebo Jakarta Timur tentang hubungan pengetahuan tentang menopause dengan tingkat kecemasan pada wanita premenopause, maka peneliti dapat mengambil kesimpulan sebagai berikut : Sebagian besar responden di Rumah Sakit Harapan Bunda Jakarta Timur Tahun 2012 memiliki pengetahuan yang tinggi tentang menopause. Sebagian besar responden di Rumah Sakit Harapan Bunda Jakarta Timur Tahun 2012 memiliki kecemasan yang ringan pada masa premenopause. Ada hubungan yang bermakna antara pengetahuan tentang menopause dengan tingkat kecemasan pada wanita premenopause di Rumah Sakit Harapan Bunda Kecamatan Pasar Rebo Jakarta Timur Tahun 2012.

\section{Saran}

Berdasarkan hasil penelitian terdapat beberapa hal yang perlu direkomendasikan untuk penelitian yang terkait dengan topik penelitian ini yaitu: Diharapkan dengan adanya penelitian ini dapat memberikan masukan kepada setiap perawat untuk selalu memberikan edukasi pada wanita premenopause untuk mengurangi tingkat kecemasan. Diharapkan dengan adanya penelitian ini dapat memberikan masukan kurikulum di mata kuliah keperawatan maternitas untuk dapat meningkatkan kualitas proses pembelajaran yang terkait dengan asuhan keperawatan pada wanita premenopause. Diharapkan dengan adanya penelitian ini dapat memberikan informasi melalui seminar pelatihan bagi pelayanan kesehatan tentang menopause yang berhubungan dengan tingkat kecemasan pada masa premenopause dengan menyediakan ruang konsultasi masalah reproduksi di berbagai jenjang pelayanan kesehatan. Guna penelitian ilmiah ini maka diharapkan adanya kelanjutan dari penelitian tentang perbedaan tingkat kecemasan tentang menopause pada wanita premenopause yang menikah, janda, dan tidak menikah.

\section{Daftar Pustaka}

1. Astini. Hubungan Antara Persepsi Dukungan Sosial yang diterima Wanita Dewasa Madya dengan Tingkat Kecemasan di Puskesmas Grogol Jakarta Barat. Tidak di publikasikan; 2007.

2. Setiono. Menopause dan Andropause, Jakarta : Yayasan Bina Pustaka; 2004.

3. Ayu IC. Memahami Kesehatan Reproduksi Wanita. Jakarta : Penerbit EGC; 2009.

4. Azwar S. Sikap Manusia Teori dan Pengukurannya. Yogyakarta: Pustaka Pelajar; 2007.

5. Bertenz K. Psikoanalisis Sigmund Freud. Jakarta: Gramedia Pustaka Utama; 2008.

6. Bobak LJ. Buku Ajar Keperawatan Maternitas, Edisi 4. Jakarta: ECG; 2005.

7. Brockopp D. Foundamentals of Nursing Research.; 2001.

8. Arikunto. Prosedur Penelitian. Edisi Revisi V. Jakarta: Rineka Cipta.2000.

9. Arikunto. Prosedur Penelitian. Edisi Revisi. Jakarta: Rineka Cipta; 2006.

10. Dinaryanti. Hubungan Tingkat Pengetahuan Tentang Menopause dengan Tingkat kecemasan Pada Wanita Usia 40-50 dalam Menghadapi masa Menopause di Kelurahan Tanjung Priok Jakarta Utara. Tidak Di publikasikan; 1999.

11. Dalami E. Asuhan Keperawatan Jiwa dengan masalah Psikososial, Jakarta : CV. Trans Info Medika.2009.

12. Hastono S. Modul Analisa Data. Jakarta : FKM UI;2004.

13. Hawari D. Management Stres, Cemas dan Depresi, Jakarta : FIK UI;2004.

14. Hidayat. Metode Penelitian Keperawatan dan Teknik Analisis Data. Jakarta: Salemba Medika; 2005.

15. Kartono. Gangguan-gangguan Psikologis. Bandung : Sinar Baru; 2005.

16. Kasdu D. Kiat Sehat di Usia Menopause. Jakarta: Puspa Swara.2005.

17. Notoatmodjo S. Promosi Kesehatan: Teori dan Aplikasi. Jakarta: Rineka Cipta; 2005.

18. Notoatmodjo S. Metodologi Penelitian Kesehatan. Edisi Revisi. Jakarta: Rineka Cipta; 2005.

19. Nursalam.Konsep dan Penerapan Metodologi Penelitian Ilmu Keperawatan. Jakarta: Salemba Medika. 2005.

20. Proverawati A. Menopause dan Sindrom Premenopause. Yogyakarta : Nuha Medika; 2005.

21. Sanito. Seluk Beluk Menopause. Yogyakarta : Gara Ilmu; 2010.

22. Sarwono. Wanita \& Gizi Menopause. Jakarta: Balai Penerbit FKUI; 2003. 